\title{
OS CAMINHOS ENTRELAÇADOS DAS DOCENTES DO INSTITUTO PROFISSIONAL FEMININO ORSINA DA FONSECA (IPFOF)
}

\author{
THE INTERLACED PATHS OF THE TEACHERS OF THE FEMALE PROFESSIONAL INSTITUTE \\ ORSINA DA FONSECA (IPFOF)
}

https://orcis.org/0000-0003-1970-4975 Teresa Vitória Fernandes Alves A

${ }^{\text {A }}$ Faculdade São Judas Tadeu (SJT), Rio de Janeiro, RJ, Brasil

Recebido em: 1 maio 2021 | Aceito em: 29 ag. 2021

Correspondência: Teresa Vitória Fernandes Alves (teresavalves@hotmail.com)

\begin{abstract}
Resumo
O presente artigo tem como objetivo discutir a trajetória de três professoras que atuaram no Instituto Profissional Feminino Orsina da Fonseca (IPFOF) entre as décadas de 1910 e 1935. É de fato intrigante que as pesquisas referentes à essa instituição não ressaltem a história dos grandes nomes femininos atrelados a história da instituição, tais como, das professoras Leolinda Daltro e Lucília Guimarães Villa-Lobos. A pesquisa que embasa a escrita desse artigo insere-se no campo da História da Educação Feminina no Brasil, objetivando analisar a atuação de mulheres no magistério sendo essas responsáveis pela instrução de meninas e moças órfãs partindo de novos métodos de ensino e de organização do espaço escolar, com base nas ideias pedagógicas que são implantadas dentro do IPFOF. Quando se aborda a história das escolas femininas logo se argumenta que elas serviam para formar mulheres prontas para serem boas esposas, mãe de família, do lar ou trabalhadoras para a indústria e comércio, mulheres prendadas, rendeiras, dedicadas aos trabalhos de linha e agulha. Contudo apesar de muitas pesquisas apontarem esse destino para o Instituto Profissional Feminino Orsina da Fonseca, como se dentro de seus muros pudéssemos encontrar uma grande colmeia laboriosa, cabe ressaltar as singularidades que nos despertam curiosidades e destoam deste cenário de cama e mesa.
\end{abstract}

Palavras-chave: profissão docente; magistério feminino; trajetória; Brasil República. Instituto Profissional Feminino.

\begin{abstract}
This article aims to discuss the trajectory of three teachers who worked at the Orsina da Fonseca Female Professional Institute (IPFOF) between the 1910s and 1935s. women linked to the history of the institution, such as the professors Leolinda Daltro and Lucília Guimarães Villa-Lobos. The research that supports the writing of this article is in the field of the History of Women's Education in Brazil, aiming to analyze the role of women in teaching, who are responsible for the instruction of orphan girls and young women, based on new teaching methods and space organization school, based on the pedagogical ideas that are implemented within the IPFOF. When approaching the history of girls' schools, it is immediately argued that they were used to train women ready to be good wives, mothers, housewives or workers for industry and commerce, gifted women, lacemakers, dedicated to needle and thread work. However, despite many researches pointing this destiny to the Orsina da Fonseca Female Professional Institute, as if within its walls we could find a large laborious beehive, it is worth emphasizing the singularities that arouse curiosity and clash with this bed and table scenario.
\end{abstract}


Keywords: teaching profession; female teaching; trajectory. Brazil Republic. Women's Professional Institute.

Da mesma forma que um artesão transforma os fios que tece em uma bela tela, o ato de fazer história termina por ser uma prática que buscará nos arquivos, documentos orais, escritos ou iconográficos informações que, uma vez analisadas, romperão um silêncio existente.

Para o historiador, não existem simplesmente fatos históricos. Na verdade, é a questão que constrói o objeto histórico (DOSSE: 2003, 17) e, essa termina por auxiliá-lo a delimitar um problema. O passado, por si só, não é um objeto de análise, é preciso que ele seja construído com tal. Logo, para que a História se diferencie de uma simples narração, o pesquisador precisa se utilizar de regras científicas e conceitos que o auxiliarão a analisar, criticar os documentos e a transformá-los em "provas" históricas.

Cabe aqui lembrar, ainda, que essa questão em si, possui uma raiz social. A investigação deve responder aos questionamentos feitos pelo historiador que está inserido em um dado momento e em uma dada sociedade, totalmente diferente daquele em que o documento foi forjado.

Os elementos desse artigo foram detalhadamente pensados e moldados, da mesma maneira que um artesão, minuciosamente, dispõe um fio sobre outro, dando forma ao seu pensamento. Como num grande quebra-cabeça, onde cada peça se encaixa em um determinado local, os fatos históricos precisam ser integrados para comporem "a" ou "as" imagens de uma dada sociedade. Ao optar por fazer uma história que analisa a vida das pessoas comuns, terminamos por nos debruçar sobre as mais diversas experiências sociais que passaram a ser o fio condutor da nossa análise.

No caso aqui tratado, a análise dos documentos existentes no arquivo permanente da Escola Municipal Orsina da Fonseca, no Rio de Janeiro, nos remete ao passado de um país onde meninas órfãs e pobres, os (as) seus (suas) professores (as) e os (as) funcionários (as) estavam submetidos às regras de uma sociedade hierárquica e fechada.

No momento em que encontramos nos arquivos da escola documentos como leis, decretos, regimentos internos, programas, grades curriculares, fichas de matrícula de ex-alunas, fichas de ex-professores (as) e funcionários (as), um campo de possibilidades para reconstituir e refletir acerca do processo social e histórico forjado dentro do Instituto Profissional Feminino Orsina da Fonseca (IPFOF). Assim, passamos a perceber e a entender que o universo desse "pequeno grupo" era muito mais amplo e terminava por influenciar não apenas a vida deles (as) 
como também de outras pessoas. Logo, um emaranhado de dados passa a fazer sentido, apesar das muitas peças isoladas, aparentemente inúteis ou estranhas, que insistem em nos desafiar no processo de construção da trajetória de professoras no magistério primário da Cidade do Rio de Janeiro.

Esses (as) verdadeiros (as) atores (atrizes) sociais refletem em suas ações e histórias pessoais as transformações ocorridas em sua sociedade. Para isso as informações do seu dia a dia, como num grande jogo de peças, permitem a reconstrução de uma parcela dos resultados da política educacional brasileira, aqui no caso desse artigo entre os anos 1912 até 1935, momento em que três professoras passam a atuar na instituição.

Observando a trajetórias dessas mulheres dentro do instituto, algumas questões surgem para conduzir nossa pesquisa. Logo, quais as disciplinas que ministravam? Como conduziam as atividades desenvolvidas junto as alunas? Como viam e valorizavam a educação? Quais suas preocupações frente a formação das meninas e moças? As respostas para algumas dessas perguntas começam a surgir no momento que alguns documentos encontrados dentro do $\mathrm{CMOF}$, tornam-se fontes importantes para a reconstrução da trajetória das alunas e professoras do IPFOF.

Atrelado a isso o discurso ideológico que envolvia a participação da mulher na carreira docente, ganha destaque em decorrência da ideia de que essa seria a profissão que conciliaria as atividades domésticas e de mãe, pois cuidar e educar crianças eram missões femininas.

A feminização do magistério além de ser uma solução para a falta de profissionais atuando nas escolas de ensino primário no território nacional, permitiu a entrada das mulheres no mundo do trabalho, transformando as escolas primárias em um espaço de lutas e disputas entre homens e mulheres.

E como professoras essas mulheres teriam a possibilidade de se inserirem no espaço público. Deste modo, a feminização do magistério abriu portas para o mercado de trabalho. A mulher, e agora professora se tornaria mais independente, pois estaria não só saindo em busca do seu próprio sustento, como também do poder e da dominação masculina da época, sendo este um passo para a emancipação feminina no processo educativo e no espaço público. (RABELO; COSTA; MARTINS: 2015, 02 - 03)

Associada a formação profissional dessas moças encontra-se também a questão da construção de um profissional que difunda uma ordem moralizante, cívica e civilizadora de sociedade que deve se dar através de uma educação voltada para a população. Pois, como afirma Guacira Louro:

Ela precisaria ser, em primeiro lugar, a mãe virtuosa, o pilar de sustentação do lar, a educação das gerações do futuro. A educação da mulher seria feita, portanto, para além dela, já que a sua justificativa não se encontrava em seus próprio anseios ou 
necessidades, mas em sua função social de educadora dos filhos, na linguagem republicana, na função social de formadora dos futuros cidadãos. (LOURO: 1997, 447)

Pautado nesse olhar, constrói-se uma nova condição social feminina dentro do magistério, o que fez surgir certos mecanismos de discriminação e de controle contra as mulheres além de implantar pensamentos/ ideologias ligadas à domesticidade e maternagem, que foram sendo reforçadas pelas normas higienistas e positivistas presentes nas práticas sociais ao longo do período da Primeira República.

Nesse momento a escolarização da população de baixa renda vincula-se ao aumento da produção de manufaturados o que favoreceu a reorganização da sociedade civil objetivando, principalmente, o amparo e retirada de meninos e meninas órfãos das ruas das grandes cidades como, também oportunizar o aprendizado de um ofício.

Quando se aborda a história das escolas femininas logo se argumenta que elas serviam para formar mulheres prontas para serem boas esposas, mãe de família, do lar ou trabalhadoras para a indústria e comércio, mulheres prendadas, rendeiras, dedicadas aos trabalhos de linha e agulha. Contudo apesar de muitas pesquisas apontarem esse destino para o Instituto Profissional Feminino Orsina da Fonseca, como se dentro de seus muros pudéssemos encontrar uma grande colmeia laboriosa, cabe ressaltar as singularidades que nos despertam curiosidades e destoam deste cenário de cama e mesa.

É de fato intrigante que as pesquisas referentes à essa instituição não ressaltem a história dos grandes nomes femininos atrelados a sua história, tais como, das professoras Leolinda Daltro e Lucília Guimarães Villa-Lobos. Mulheres, que lutaram para o reconhecimento de mulheres para além do espaço doméstico e do lugar de operária da fábrica. A biografia destas mulheres nos leva a questionar: as alunas-abelhas do Instituto Profissional Feminino Orsina da Fonseca (IPFOF) eram meras reprodutoras do discurso hegemônico da sociedade a respeito dos espaços que deveriam ocupar e do que deveriam ser?

Este artigo tem um compromisso político com a História do Tempo Presente, no momento que busca dar visibilidade a história de mulheres, professoras, mães, política e suas atuações em diferentes espaços, mas, fundamentalmente, na educação laica de mulheres. Considero importante destacar a história de Leolinda de Figueiredo Daltro e Lucília Villa Lobos em um artigo que visa discutir gênero e sexualidade pelo o QUÊ na sua história contribui para refletirmos sobre os movimentos feministas e as transgressões de gênero que podem ocorrer no campo da educação. 
Neste artigo entende-se gênero como a construção social e histórica que faz parte de um sistema de pensamento e linguagem binário (sexos masculino ou feminino) que se coloca em oposição e, ao mesmo tempo, em completude. Isto é, utilizamos como referencial os trabalhos de Judith Butler (2016) que denunciam a coerência sexo-gênero e desejo (sexo feminino, gênero feminino e desejo pelo sexo masculino) em conformidade com a matriz heterossexual e que contribuem, por tanto, para a reprodução das performances femininas e masculinas.

Em se tratando do Brasil da Primeira República as performances esperadas para as mulheres eram aquelas que visavam desde o celibato para professoras solteiras até as reproduções de gênero femininos vinculadas ao recôndito do mundo doméstico. Lembrando que as escolas foram fundamentais no sucesso da permanência dessas performances de gênero, pois é nesta instituição que essas que essas eram ensinadas e consolidadas.

\title{
A educação na cidade do Rio de Janeiro na virada do século XIX para o século XX
}

\begin{abstract}
Este enraizamento das mulheres no território de seus corpos é uma das chaves de sua extrema dificuldade em ter acesso ao assalariamento, mesmo como operárias. Pois a revolução industrial não traz para elas, num primeiro momento mudança radical, mas sim a extensão de sua escravidão, ampliada do círculo familiar para o ateliê e para a fábrica, com as mesmas características de não qualificação de precariedade de emprego e de dependência sexual. A contratação, a promoção, as gratificações estão nas mãos de uma direção e de executivos masculinos, fortemente tentados a usar de suas prerrogativas para tirar dali todo o prazer possível. Ainda mais quando a mãode-obra é jovem - as operárias tinham de onze ou doze anos, até vinte e vinte cinco anos - fresca, virgem e sem defesa. (PERROT: 2005,448 - 449).
\end{abstract}

Em fins do século XIX tem-se a universalização do ensino primário nos Estados Unidos da América e em vários países da Europa também. Logo a educação individual dá lugar ao modelo de ensino simultâneo, onde no espaço escolar começam a se formar várias classes primárias e secundárias, onde inúmeros professores e professoras passam a atuar. Nesse momento, a mulher passa a ter um destaque no magistério primário, onde transforma-se em profissional da educação.

Nas décadas finais do século XIX e nos anos iniciais do século XX, em vários países ocidentais, as mulheres foram recrutadas tanto para as salas de aula, primárias e do curso normal, como para funções de direção de escolas primárias, jardins de infância, grupos escolares e escolas modelos e, em menor escala, para funções de inspeção escolar. (RIZZINI; SCHUELER: 2020, 43)

Nesse momento tanto em Portugal quanto no Brasil observa-se uma expansão no que se refere a feminização do magistério. Nessa fase o trabalho feminino no espaço escolar ocorre a partir de uma necessidade moral presente em ambos países, já que a sociedade não via com bons olhos destinar nas mãos de professores a função de educar meninas e moças, além da 
recusa desse mesmo grupo em difundir escolas de coeducação, prática vista como perigosa, onde meninos e meninas ocupariam o mesmo espaço escolar.

No sistema escolar de Portugal e do Brasil, as autoridades do ensino voltaram-se para as mulheres por considerar que estas preenchiam as condições profissionais exigidas para a escola pública que se expandia e se alicerçava em cada país. Porém, é importante ressaltar que além da atenção do poder público e da área educacional, que pretendia reservar às mulheres a fatia do mercado de trabalho representado pelo magistério, também houve, por parte destas, um movimento em direção à profissão e uma consequente ocupação desse espaço resultante de uma capacidade de reivindicar. Talvez fossem reivindicações brandas, bem no estilo português e brasileiro de ser, sem grandes embates e confrontos, no entanto, impulsionaram as mulheres ao mundo do trabalho e à inserção no espaço público, numa primeira vaga que representou o início de mudanças para a condição feminina nos dois países. (ALMEIDA: 1998, 141)

No momento em que o Estado criou condições para a participação feminina no magistério de forma remunerada tem-se uma grande procura pelo ofício. Atrelado a isso o discurso ideológico que envolvia a participação da mulher no magistério ganha destaque em decorrência da ideia de que essa seria a profissão que conciliaria as atividades domésticas e de mãe, pois cuidar e educar crianças fazia parte da missão feminina.

Observa-se que em várias províncias do Império era destinado às meninas órfãs a carreira no magistério primário, alternativa paralela ao casamento ou as atividades como domésticas. Como base de sua formação profissional essas meninas e moças ao frequentarem as Escolas Normais, deveriam estudar as seguintes disciplinas:

(...) língua nacional; língua francesa; aritmética, álgebra e geometria; metrologia e escrituração mercantil; geografia e cosmografia; história universal; história e geografia do Brasil; elementos de ciências físicas e naturais e de fisiologia e higiene; filosofia; princípios de direito natural e de direito público, com explicação da Constituição Política do império; princípios de economia política; noções de economia doméstica (para as alunas); pedagogia e prática do ensino primário em geral; prática do ensino intuitivo ou lição de coisas; princípios de lavoura e horticultura; caligrafia e desenho linear; música vocal; ginástica; prática manual de ofícios (para os alunos); trabalhos de agulha (para as alunas); instrução religiosa (não obrigatória para os acatólicos). (TANURI: 2000, 67)

As diferenças em algumas disciplinas do currículo básico para a formação docente, descritas acima, marcam as distinções sexuais presentes no mundo do trabalho além de firmar as concepções existentes na época, sobre as práticas de natureza biológica em relação ao sexo masculino e feminino.

Associada a formação profissional dessas moças encontra-se também a questão da construção de um profissional que difunda uma ordem moralizante, cívica e civilizadora de sociedade que deve se dar através de uma educação voltada para a população. Diante desse propósito tanto o Estado quanto às elites dirigentes identifica na formação profissional docente das mulheres não apenas uma questão de direito natural, já que traziam em sua constituição 
feminina, mas uma mudança no posicionamento social pois a inserção no mercado de trabalho teria um papel de destaque na luta das mulheres pela conquista do trabalho digno e remunerado.

O aumento de ofertas de trabalho para elas no sistema educacional transforma-se num marco, uma conquista por parte dessa parcela da população e a inclusão delas no universo profissional e sociocultural brasileiro.

O processo de feminização do magistério passa a ser um fato que marca o período republicano, onde a atuação de professores se faz nas escolas masculinas e das professoras nas escolas femininas e de ensino misto. Pois, como afirmam as professoras Alessandra Schueler e Irma Rizzini (2018, 01), “o processo de "feminização do magistério" primário não pode ser compreendido sem a reflexão relacional de sua contrapartida, ou seja, a "desmasculinização".

Esse padrão profissional, já alicerçado no Império, consolidou-se mais ainda na República e só veio aumentar nos anos que decorreram, pois dentro do projeto educacional dos republicanos estava a questão da difusão da instrução popular pautada na crença de que a nação só cresceria através da propagação da educação.

Por vezes atrelou-se a entrada da mulher a desvalorização da profissão, contudo esse processo ultrapassa a questão sexual chegando, realmente, na questão central de que o magistério deixava de atender apenas as elites da sociedade voltando-se para a população de baixa renda, fato esse observado tanto no Brasil quanto em Portugal. Nesse momento tanto a ampliação da rede escolar quanto a entrada das mulheres na profissão docente traz consigo a ideia de que elas poderiam moralizar a sociedade.

Sob essa ótica constrói-se uma nova condição social feminina dentro do magistério, o que fez surgir certos mecanismos de discriminação e de controle contra as mulheres além de implantar pensamentos/ ideologias ligadas à domesticidade e maternagem, que foram sendo reforçadas pelas práticas higienistas e positivistas presentes nas práticas sociais ao longo do período da Primeira República.

Nesse momento a escolarização da população de baixa renda vincula-se ao aumento da produção de manufaturados o que favoreceu a reorganização da sociedade civil objetivando, principalmente, o amparo e retirada de meninos e meninas órfãos das ruas das grandes cidades como, também oportunizar o aprendizado de um ofício. E, à frente dessa proposta encontravamse os representantes da elite econômica e social do país.

Inserido nesse projeto encontramos o Instituto Profissional Feminino, que surge no cenário educacional brasileiro no ano de 1877 com base na proposta difundida pelo imperador D. Pedro II de criar instituições que abrigassem meninos e meninas órfãos. Assim, foi criado o 
Instituto Profissional Feminino, localizado na Freguesia do Engenho Velho, atual bairro da Tijuca, na cidade do Rio de Janeiro, que naquele momento era a capital do Império brasileiro. Dez anos depois em 1897, essa instituição será reinterpretada pelos líderes da Primeira República e que faz com que o antigo instituto profissional, criado a partir de uma política educacional pensada ainda no reinado de D. Pedro II, ganhe uma nova estrutura além de uma um novo espaço arquitetônico e um novo endereço dentro da mesma freguesia inicial.

Segundo o Decreto n ${ }^{\circ} 836$, de 20 de outubro de 1911, desde o seu nascimento o instituto nasce com objetivos diferentes das escolas profissionais, pois o mesmo possuía o regime de externato e internato e deveria ser dirigido por mulheres.

A Escola surge por força do decreto n. 838, de 20 de outubro de 1911, que determina, entre outras coisas, a criação de uma rede de vinte escolas profissionais, das quais dez destinadas ao sexo masculino e dez ao sexo feminino. Dois anos depois, por força do decreto n. 912, de 10 de maio de 1913, do prefeito general Bento Ribeiro11, seguindo a lógica da denominação dada às escolas primárias da época separadas para meninos e meninas12, são criadas a " $1^{\mathrm{a}}$ Escola Profissional Feminina" e a " $2^{\mathrm{a}}$ Escola Profissional Feminina", nos moldes do já existente Instituto Profissional Feminino, em regime de externato e devendo ser regida e dirigida por mulheres. (BONATO: 2008, 87)

A criação dos Institutos Profissionais tanto o feminino quanto o masculino estão em consonância com o projeto político republicano que buscava uma transformação tanto no campo social quanto no espaço de educação popular, produziu uma nova cultura escolar que repercutiu de forma ampla e significativa na sociedade carioca, no momento que ressignificou a educação no meio urbano e, assim, conduziu a consagração do modelo republicano.

O Instituto Profissional Feminino, que tem sua origem no bairro da Tijuca na zona norte da cidade do Rio de Janeiro, passou a ser referência enquanto espaço de formação para meninas das classes mais populares. Além disso, a maioria daqueles (as) que ali trabalharam e estudaram puderam presenciar e receber as influências das transformações educacionais que a cidade do Rio de Janeiro viria a sofrer enquanto capital da República.

Toda essa ótica em relação ao modelo educacional estava associada ao processo de modernização da sociedade. Ligada a questão da industrialização. Nasce um discurso de integralização do indivíduo associado ao ideário de civilização, progresso e ordenamento e que construía um olhar para questão da profissionalização.

A proposta de profissionalização das meninas vem acompanhada por mudanças nas estruturas das escolas, o que nos leva a perceber que o olhar direcionado a essa instituição transforma-se e, agora, passa a ser relacionada ao progresso da Nação. 
As mudanças nas estruturas do ensino revelam um olhar diferenciado acerca do papel das escolas na construção da cidadania e, no caso em particular, o lugar a ser ocupado pelas mulheres neste reordenamento social, o qual vai concretizar a ideia de uma Nação que se alicerçava com base em um projeto de nacionalidade frente as transformações de uma "nova" sociedade que precisava responder às demandas do processo de industrialização que o país estava iniciando.

\section{Os fios que entrelaçam duas trajetórias no IPFOF}

Muito além de render bons produtos para a indústria e comércio de indumentárias, como afirmou Afrânio Peixoto em "Educação da Mulher" (1936), devemos nos esforçar e erguer novos olhares para um mesmo objeto de estudo, já que a professora Leolinda Daltro defendia treinamento militar para as suas alunas em plena praça pública, a criação da linha de tiro feminino do IPFOF, onde as mulheres poderiam receber treinamentos de armas de fogo, defensora da alfabetização laica dos indígenas, do divórcio e fundadora do Partido Republicano Feminino (MELO; MARQUES: 2010).

Leolinda Daltro com seu salário de professora sustentou cinco filhos, contudo, antes disso percorreu regiões longínquas do país em defesa da alfabetização indígena e da integração destes na sociedade. Como esperar que tendo uma professora que deixou o marido e os filhos em defesa do seu ideal durante alguns anos poderia promover uma escola que preparasse mulheres apenas para as prendas do lar ou quiçá uma boa operária? A trajetória biográfica de D. Leolinda é um indício que há muito mais na história dessa instituição. Há relações de poder, de resistência, há disciplina, mas, há promoção de novas ideias e de luta pelo reconhecimento da igualdade entre homens e mulheres. Sua biografia torna possível uma nova leitura do social, onde é possível estabelecer a articulação entre biografia e história, entre a história individual e o tempo social (BALLAN; JELLI, apud ABREU: 2010, 97).

Como afirma Alzira Abreu "Uma biografia sempre narra acontecimentos" (2010, 97), os acontecimentos narrados na biografia de Leolinda Daltro nos servem de pistas para compreender esse outro lado da história do IPFOF e um bom exemplo do trabalho realizado por essa mulher foi à criação do Clube de Tiro direcionado às alunas do IPFOF onde o treinamento militar em praça pública e a marcha com as meninas pelo Partido Republicano Feminino foram algumas das atividades encabeçadas por essa mulher, mãe e educadora ainda na Primeira República. 
Leolinda Daltro, baiana, cuja data de nascimento supõe-se ser de 1859, ao acompanhar seu marido mudou-se para a capital imperial - Rio de Janeiro, onde passou atuar como professora no magistério público municipal e, foi como docente que sustentou uma família de cinco filhos frutos de dois casamentos.

No Rio de Janeiro teve contato com um grupo indígena Xerente - o que a levou para os sertões do norte de Goiás, hoje, Tocantins com a finalidade de proporcionar uma educação laica aos indígenas. Da sua missão com os indígenas de Goiás saiu o seu livro "Da catequese dos índios no Brasil”. Esta não seria a única obra de Leolinda que, em 1918, publicou seu segundo livro denominado "Início do feminismo no Brasil". Deste modo ela é considerada uma das primeiras antropólogas do Brasil (CORRÊA: 1989) por seu trabalho indígena e precursor do Movimento Feminista Brasileira, tendo fundado o Partido Republicano Feminino, em 1910.

$\mathrm{Na}$ revisão bibliográfica sobre Leolinda Daltro encontram-se teses e artigos que destacam, principalmente, seu trabalho com indígenas. Sendo, neste sentido, reconhecida internacionalmente (SANTOS: 2014). Apesar desta tímida produção brasileira sobre sua história, acredito que o nome de Leolinda Daltro ainda não ganhou visibilidade e espaço à altura da sua história e da história das mulheres. Mais do que isso, acreditamos que ao revisitar fontes já estudadas e descobrir outras que envolvem sua ação como mulher, feminista e professora isso nos permite refletir sobre as relações de gênero na Educação.

Neste artigo entendemos gênero como a construção social e histórica que faz parte de um sistema de pensamento e linguagem binário (sexos masculino ou feminino) que se coloca em oposição e, ao mesmo tempo, em completude. Isto é, utilizamos como referencial os trabalhos de Judith Butler que denunciam a coerência sexo-gênero e desejo (sexo feminino, gênero feminino e desejo pelo sexo masculino) em conformidade com a matriz heterossexual e que contribuem, por tanto, para a reprodução das performances femininas e masculinas.

Em se tratando do Brasil da Primeira República as performances esperadas para as mulheres eram aquelas que visavam desde o celibato para professoras solteiras até as reproduções de gênero femininos vinculadas ao recôndito do mundo doméstico. Lembrando que as escolas foram fundamentais no sucesso da permanência dessas performances de gênero, pois é nesta instituição que essas que essas eram ensinadas e consolidadas.

Neste sentido, o trabalho de Leolinda no Instituto Profissionalizante Orsina da Fonseca se destaca por transgredir essas performances esperadas do feminino, e reproduzidas incessantemente por esse instituto por meio das oficinas de flores, corte e costura etc. Professoras de meninas pobres e órfãs, Leolinda propôs atividades diferenciadas para elas, 
como treinamento de tiro em plena Praça da República (no centro do Rio de Janeiro) e uma marcha republicana feminista até o palácio do Catete.

Para além dos conteúdos trabalhados dentro das disciplinas ministradas nas salas de aulas o espírito da nacionalidade e a ideia de uma sociedade civilizada ganham espaços através de diferentes vias: nos textos de exaltação da pátria, nas músicas e hinos cantados no Canto Orfeônico, nos desfiles e festas cívicas, que refletem a escola para além dos seus muros.

A partir da reforma educacional de Francisco Campos em 1931, ocorreram alterações no currículo do ensino secundário. Nesse momento foi incorporado à grade escolar a disciplina Canto Orfeônico. O projeto geral do governo varguista era fazer da música um elemento que permitisse desenvolver nas alunas um padrão moral, cívico e intelectual. Como grande difusor desse projeto intitulado de nacionalismo musical, o maestro Heitor Villa-Lobos, que ao lado de grandes expoentes da música brasileira, agregaram elementos presentes nas músicas populares, que em sua opinião seria a real expressão da veia artística brasileira, ao material que deveria ser trabalhado nas escolas brasileiras.

Dentre os espaços onde Villa-Lobos difunde suas ideias foi a Escola Técnica Feminina Orsina da Fonseca, onde sua esposa a pianista Lucília Villa-Lobos era a professora responsável pela edificação do Canto Orfeônico nessa escola. A primeira mudança que se tem é na grade curricular, onde entre todas as disciplinas temos o Canto Orfeônico sendo obrigatório para todas as séries.

Em 1935, dentro da proposta de iniciação à cultura musical e do projeto de cultura cívica, foi realizado no Estádio de Futebol Vasco da Gama uma grande concentração orfeônica, onde a Escola Técnica Feminina Orsina da Fonseca vai se apresentar sob a regência da pianista Lucília Villa-Lobos.

Muito além da afirmação do cívica do Canto Orfeônico em eventos públicos para difusão de um pensamento cívico nacional, a SEMA buscou disseminar entre os jovens estudantes o desejo de se fazer presente no grupo orfeônico ocupando os tempos livres dessas crianças e jovens, além de atingir de forma indireta suas famílias, propagando modelos de condutas e normas disciplinares.

O Canto Orfeônico, dentro do prisma da formação de uma consciência musical passa a ocupar um espaço de destaque. A música orfeônica agregada no currículo das escolas vai trabalhar com elementos educacionais que buscam esculpir as novas gerações, não apenas na questão da musicalidade mais principalmente no que tange à formação cívica e moral dos novos 
jovens brasileiros. Logo, o ensino musical eclode como um lugar social onde práticas de disciplina e a ideia de nação se cruzam.

\section{Conclusão}

Ao apresentar a trajetória do IPFOF e de suas professoras pretende-se difundir não apenas a trajetória educacional das docentes, mas suas formas de atuação e de transformação do cenário educacional carioca, como, também, a forma como se aproximaram das alunas do IPFOF e influenciaram suas trajetórias.

Salienta-se com essa pesquisa, ainda inicial, que essas duas docentes estiveram à frente da criação de projetos educacionais que tinham como propósitos não só transformar meninas pobres e órfãs em trabalhadoras, mas que muito além disso objetivavam propagar um modelo de educação pública que garantisse a formação de mulheres mais críticas e participativas da sociedade brasileira, destacando suas determinações com as questões das minorias e das mazelas sociais presentes não apenas na cidade do Rio de Janeiro, mas, também, em todo o território nacional.

A educação foi um caminho para jovens mulheres serem inseridas no contexto público, visando não apenas se emanciparem culturalmente, mas, também, para futuramente instruírem seus filhos, ou alcançar uma ocupação profissional que lhes permitissem melhorar renda familiar.

O processo educacional feminino não foi apenas uma resposta às necessidades que surgiram a partir do advento do capitalismo e da república brasileira, mas foi, sobretudo uma maneira dessas jovens mulheres forjarem-se enquanto cidadãs e agentes da história, desvendado suas inquietações para além do espaço privado.

\section{Referências}

ABREU, Alzira. "As revelações de um dicionário da Primeira República do Brasil”. In: MORÃO, Alda; GOMES, Angela de Castro (orgs). A experiência da Primeira República no Brasil e em Portugal. Coimbra: Imprensa Universitária, 2010.

ABREU, Alzira \& BELOCH, Isabel (org). Dicionário Histórico-Biográfico Brasileiro pós30. $2^{\mathrm{a}}$ Ed. Rio de Janeiro: Editora FGV/ CPDOC, 2001.

ALMEIDA, Jane Soares de. Mulher e educação: a paixão pelo possível. São Paulo: UNESP, 1998. 
BALAN, Jorge; JELIN, Elizabeth. La structure sociale dans la biographie personnelle. Cahiers Internationaux de Sociologie, v. LXIX, 1980.

BONATO, Nailda Marinho da Costa. "Imagens da escola profissional feminina no distrito federal". Disnonível em:

$<$ http://www.histedbr.fe.unicamp.br/revista/revis/revis09/art17_9.html >. Acesso em: 15 SET. 2020

BUTLER, Judith. Problemas de gênero: feminino e subversão da identidade. Rio de Janeiro: Civilização Brasileira, 2016.

DOSSE, F. A História. Bauru, SP: EDUCS, 2003.

CORREAA, Mariza. "Os índios do Brasil elegante \& a professora Leolinda Daltro". In: Em Antropólogas \& antropologia. editado por Mariza Corrêa. Belo Horizonte: Editora UFMG, 2003.

CUNHA, Paulete Maria. Leolinda Daltro, a caminhante do futuro: uma análise de sua trajetória de catequista a feminista (Rio de Janeiro/ Goiás - 1896 - 1920). São Leopoldo, 2014. Disnonível em:

<http://www.repositorio.jesuita.org.br/bitstream/handle/UNISINOS/4097/Paulete\%20Maria\% 20Cunha\%20dos\%20Santos.pdf?sequence=1\&isAllowed=y >. Acesso em 10 abr. 2021.

GOMES, Ângela de Castro. "A escola republicana: entre luzes e sombras”. In: A República no Brasil. Rio de Janeiro: Nova Fronteira; CPDOC/FGV, 2002.

GRAMSCI, Antônio. Os intelectuais e a organização da cultura. Rio de Janeiro: Civilização Brasileira, 1991.

LE GOFF, Jacques. História e Memória. 4ª edição. Campinas: Unicamp, 1996.

LOURO, Guacira Lopes. Gênero, sexualidade e educação. Uma perspectiva pósestruturalista. Petrópolis, RJ: Vozes, 1997.

. "Uma leitura da história da educação sob a perspectiva do gênero".

In: Projeto História. São Paulo, 11 nov, 1994.

McLAREN, P. Rituais na Escola: em direção a uma economia política de símbolos e gestos na educação. Petrópolis: Vozes, 1992.

MELO, Hilda Pereira de; MARQUES, Teresa Novaes. "Partido Republicano Feminino - A construção da cidadania feminina no Rio de Janeiro". In: Revista do Instituto Histórico e Geográfico do Rio de Janeiro. Rio de Janeiro, 2010.

MOURÃO, Alda; GOMES, Angela de C. (Coord). A experiência da Primeira República no Brasil e em Portugal. Coimbra (PT): Universidade de Coimbra, 2016.

PERROT, Michele. As mulheres e os silêncios da História. Bauru, SP: EDUSC, 2005. 
RABELO, Josiane O.; COSTA, Marta O.; MARTINS, Bárbara T. de S. A educação feminina no Brasil em meados do século XIX e início do século XX. In: Encontro Internacional de Formação de Professores e Fórum Permanente de Inovação Educacional, 2015.

ROCHA, Paolla Rolon; SEVERINO, Jorismary Lescano; RODRÍGUEZ, Margarita Victoria. "Era Vargas (1930-1945): notas sobre o ensino secundário". Disnonível em: <https://www.brazilianjournals.com/index.php/BRJD/article/view/22608>. Acesso em: 24 jun. 2021.

RIZZINI, Irma; SCHUELER, Alessandra F. de M. “"O feminismo transborda”: docência, produção escrita e atuação política de Aurea Corrêa na cidade do Rio de Janeiro". In: Revista Práxis Educacional. Vitória da Conquista, Bahia, 2020.

SANTOS, Paulete Maria C. Leolinda Daltro, a caminhante do futuro: uma análise de sua trajetória de catequista a feminista (Rio de Janeiro/Goiás - 1896/1920). São Leopoldo, RGS, 2014. Tese de Doutorado.

SCHUELER, Alessandra F. M. de; RIZZINI, Irma. Gêneros e constituição do magistério primário: "feminização" e "desmasculinização" no Rio de Janeiro (1870-1910). Disnonível em: 〈http://www.sitioftp.com/EventosOPC/programa/resumenes/EJE7/eje7_183.pdf〉. Acesso em 03 set. 2021.

TANURI, Leonor Maria. "História da Formação de Professores". In: Revista Brasileira de Educação. Campinas: n.14, p. 61-88, mai./jun./jul./ago., 2000. 